\title{
EFFECT OF DIFFERENT SURFACE TREATMENT MODALITIES ON CRYSTAL STRUCTURE AND BIAXIAL FLEXURAL STRENGTH OF SUPER TRANSLUCENT ZIRCONIA
}

\author{
Lamia E. Dawood* and Mahy H. Hassouna **
}

\begin{abstract}
Objectives: To study the outcome of different surface treatments on $\mathrm{X}$ ray diffraction analysis (XRD) and flexural strength of super translucent zirconia.

Materials and Methods: Forty identical discs were milled from presintered super translucent zirconia blank (VITA YZ ST, VITA Zahnfabrik, Germany). Specimens were classified into 4 groups according to the surface treatment used: Group C: no treatment (control group), Group S: discs were airborne particle, Group P: discs were treated with primer and Group SP: discs were airborne particle then, they were treated with primer. All specimens were subjected to XRD analysis and biaxial flexural strength test.
\end{abstract}

Results: The highest biaxial flexural strength recorded value was for the $C$ group $(462.11 \pm 17.33$ MPa) while the lowest one was recorded for S group $(310.33 \pm 7.78 \mathrm{MPa})$. Applying one way ANOVA and Tukey test revealed a statistically significant difference among all tested groups. The XRD analysis of specimens that were treated with different surface treatments revealed the evolution of monoclinic phase transformation in groups S and SP.

Conclusions: The airborne particle abrasion resulted in the evolution of tetragonal to monoclinic phase transformation on the zirconia surface which in turn negatively affected the flexural strength of super translucent zirconia.

KEYWORDS: Super translucent zirconia, Biaxial flexure strength, Airborne particle abrasion, Primer, XRD.

\section{INTRODUCTION}

In recent decades, the increased need for esthetic led to the replacement of metal-ceramic restorations with indirect metal-free ones. ${ }^{1}$ Zirconia has gained an important role in these cases, because of its superior mechanical and biocompatible properties. ${ }^{2}$ In the past, it was used only as frameworks for allceramic restorations. Lastly, with the development of translucent zirconia with its superior esthetic characteristics, allowed for the use of monolithic

\footnotetext{
* Associate Professor, Fixed Prosthodontics Dept., Faculty of Dentistry, Mansoura University, Mansoura, Egypt

** Assistant Professor, Fixed Prosthodontics Dept., Faculty of Dentistry, Mansoura University, Mansoura, Egypt
} 
prosthesis with numerous advantages; elimination of chipping problems, favorable mechanical properties, manufacturing of thinner restorations resulting in a more conservative dental preparation and the possibility of manufacturing by CAD/CAM method. ${ }^{3,4}$

Strong bond strength between fixed restoration and luting cement is obligatory for long lasting restorations, manufacturers claimed that zirconia restorations can be effectively luted with either conventional or adhesive cements, ${ }^{5}$ however, a few zirconia fixed dental prosthesis demonstrated decreased retention with their supporting abutments. ${ }^{6} \mathrm{~A}$ strong, long-standing bond between adhesive resin and zirconia restoration is set up by micromechanical interlocking and chemical bond formation. ${ }^{7}$ Achieving an efficient and stable bond with zirconia is a challenge, because zirconia is a polycrystalline material with restricted vitreous phase, neither etching with hydrofluoric acid nor silanization can accomplish strong bond between zirconia and resin. ${ }^{8}$ So, different surface treatments are presented to form a strong long-lasting bond between zirconia and resin cements.

Air abrasion is utilized to obtain mechanical interlocking, clean the superficial layer, remove contaminations, increase surface irregularities, and alter the wettability and surface energy. ${ }^{9}$

Primers have a dominant role in adhesive procedures, particularly for zirconia-based ceramics. ${ }^{10}$ Chemical surface pre-treatment of zirconia with MDP-containing primer resulted in a durable bond between resin and translucent zirconia. ${ }^{11,12}$ The adhesive functional monomers are believed to make hydrogen bonds with the metal oxides at the interface of zirconia / resin, resulting in improved wettability. ${ }^{13}$

Since results are not usually notable, the combination of primers especially those containing MDP and airborne particle abrasion is liable to form good bond strength, particularly in long term. ${ }^{14-17}$
The zirconia strength could be affected by variable surface treatment modalities, like airborne particle abrasion, silica coating, etching with acids and mixing of any of these methods ${ }^{18,19}$ Many studies revealed negative effects on zirconia strength as a result of using different surface treatments. ${ }^{20-22}$

Distinctive surface flaws were noticed after zirconia surface treatment with airborne particle abrasion, which is considered as areas of stress concentration resulting in probable crack initiation and propagation. ${ }^{23,24}$ Otherwise, some studies showed an increase in zirconia strength with airborne particle abrasion because of the creation of compressive stresses resulted from the transformation of tetragonal to monoclinic phases on the zirconia surface. ${ }^{5,25}$ Other studies considered this transformation to be responsible for deterioration of the zirconia mechanical properties. ${ }^{26-29}$ So, the target of this study was to assess the effect of variable surface treatments on $\mathrm{X}$ ray diffraction analysis and flexural strength of super translucent zirconia. The null hypotheses to be tested were that application of different surface treatments on super translucent zirconia would affect its crystalline structure and its biaxial flexure strength

\section{MATERIALS AND METHODS}

One acrylic resin disc (Pattern resin LS, GC America Inc. Alsip, IL 60803 USA) with a circumference of $12 \mathrm{~mm}$ and thickness of $1.2 \mathrm{~mm}$ was made using a special mold. ${ }^{30}$ Scanning of the disc was done using an optical scanner (Ceramill map400, Amman Girrbach, Germany). Using the special software (Ceramill Mind design software), forty identical copies of the scanned disc were designed on the presintered super translucent zirconia blank (VITA YZ ST, VITA Zahnfabrik, Germany) and dry milled using 5-axis milling machine (Ceramill Coolstream, Amman Girrbach, Germany). Sintering, finishing, and glazing of the discs were done following the manufacturer's recommendations. 


\section{Specimens grouping and surface treatments}

The discs were randomly divided into 4 groups $(\mathrm{n}=10)$ according to the surface treatment used; Group C: no treatment was used (control group), Group S: discs were airborne particle abraded with $50 \mu \mathrm{m} \mathrm{Al}_{2} \mathrm{O}_{3}$ at right angle to the surface at distance of $10 \mathrm{~mm}$ and 4 bars pressure for 20 seconds $^{5}$ (Renfert Gmbh, Germany), Group P: discs were treated with zirconia primer (Z-primer Plus, Bisco Inc, USA) by application of 2 uniform coats of primer which were dried with air spay for 5 seconds according to the manufacturer's recommendations. Group SP: discs were airborne particle abraded with $50 \mu \mathrm{m} \mathrm{Al}_{2} \mathrm{O}_{3}$ at right angle to the surface at distance of $10 \mathrm{~mm}$ and 4 bars pressure for 20 seconds then, they were treated with 2 uniform coats of zirconia primer which were dried with air spray for 5 seconds.

\section{X-Ray Diffraction analysis (XRD)}

Characterization of phase transformation of zirconia surface following the different surface treatments was performed by X-Ray Diffraction analysis (XRD). Three randomly selected specimens from each group were analyzed in a diractometer (X'Pert PRO, PANalytical co., Holland).

XRD patterns were collected using conventional $2 \theta-\theta$ method and the grazing angle method (incident angle $\theta=1^{\circ}$ and $2^{\circ}$ ) with $\mathrm{Cu} K \alpha$ radiation at $40 \mathrm{kV}$ voltage and $40 \mathrm{~mA}$ current. Diffract grams were obtained from $25^{\circ}$ to $36^{\circ}$ at a scan speed of $0.5^{\circ} / \mathrm{min}$. Rietveld analysis of XRD patterns was performed with software (Bruker AXS, Karlsruhe, Germany) to quantify phase contents and lattice parameters.

The amount of monoclinic phase (Xm) was calculated using Gravie and Nicholson equation ${ }^{31}$ as follows:

$$
X \mathrm{~m}=\frac{\boldsymbol{I m}(111)+\operatorname{Im}(-111)}{\operatorname{Im}(111)+\operatorname{Im}(-111)+\boldsymbol{I t}(111)}
$$

Where $\operatorname{Im}(\mathbf{1 1 1})$ is the monoclinic peaks intensity at $2 \theta=28^{\circ}$ and $\operatorname{Im}(-111)$ is the monoclinic peaks intensity at $2 \theta=31^{\circ}$ degrees, and It (101) is the tetragonal peaks intensity at $2 \theta=30^{\circ}$.

The volumetric fraction of monoclinic phase $(\mathrm{Vm})$ was calculated using the following equation ${ }^{32}$ :

$$
V \mathrm{~m}=\frac{0.3111 \mathrm{Xm}}{1+0.3111 \mathrm{Xm}}
$$

\section{Biaxial flexural strength test:}

All specimens were exposed to biaxial flexural strength test using piston-on-three balls technique (Figure 1), each specimen was positioned on the top of three steel balls $(3.2 \mathrm{~mm}$ in diameter and $120^{\circ}$ apart forming a tripod). Load was applied at right angle to the center of the upper surface of the specimen by a round tipped cylinder steel piston with a diameter of $1.6 \mathrm{~mm}$ at a crosshead speed of $0.5 \mathrm{~mm} / \mathrm{min}$. in a Universal Testing machine (Instron 3345, USA) using its special software (Bluehill Universal software, Instron, USA) till failure occurred. The flexural strength, in MPa, was calculated using the following equations according to the guidelines of ISO $6872,1998{ }^{33}$ :

$$
\begin{aligned}
& S=-0.2387 P(X-Y) / d^{2} \\
& X=(1+v) \ln \left(r_{2} / r_{3}\right)^{2}+[(1-v) / 2]\left(r_{2} / r_{3}\right)^{2} \\
& Y=(1+v)\left[1+\ln \left(r_{1} / r_{3}\right)^{2}\right]+(1-v)\left(r_{1} / r_{3}\right)^{2}
\end{aligned}
$$

Where $S$ is the maximum tensile stress in $\mathrm{MPa}$, $\boldsymbol{P}$ is the load at fracture $(\mathrm{N}), \boldsymbol{d}$ is thickness of the specimens $(1.2 \mathrm{~mm}), \boldsymbol{v}$ is the Poisson's ratio for zirconia (0.32), ${ }_{1}$ is the supporting ball radius (3.2 $\mathrm{mm}), \boldsymbol{r}_{2}$ is the radius of the piston tip $(1.6 \mathrm{~mm})$, and $\boldsymbol{r}_{3}$ is the specimen radius $(12 \mathrm{~mm})$.

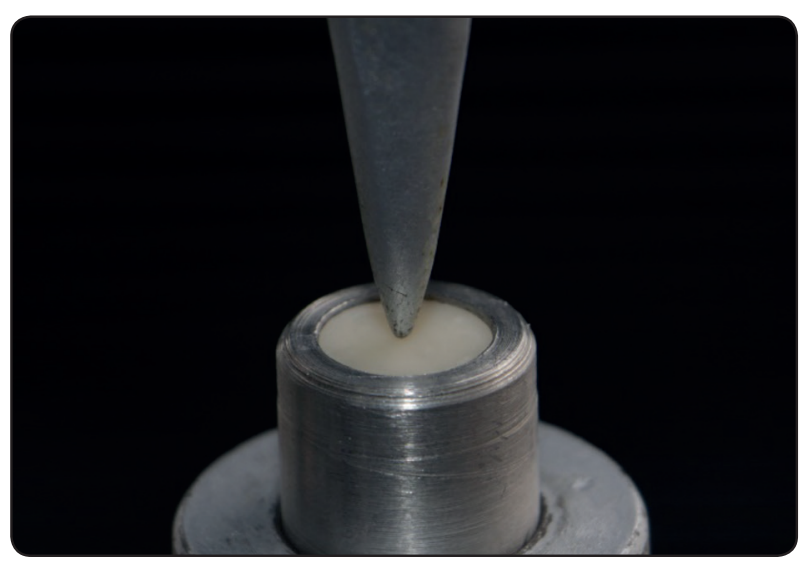

Fig. (1) Biaxial flexure strength test 
The resultant data were collected, tabulated, and analyzed statistically.

\section{RESULTS}

The XRD analysis of the different surface treatments revealed the evolution of monoclinic phase transformation in groups S and SP (Figure 2) with volumetric fraction of monoclinic phase of 6 and $7 \%$ respectively, while no phase transformation was observed in the $\mathrm{C}$ and $\mathrm{P}$ groups.

The biaxial flexure strength values and their standard deviations for all tested groups are presented in table 1 . The highest reported value was for the control group (C) $(462.11 \pm 17.33 \mathrm{MPa})$ while the lowest one was reported for the airborne particle abraded group (S) $(310.33 \pm 7.78 \mathrm{MPa})$.

Analysis of data was done in two steps; one way analysis of variance ANOVA was conducted for the comparison between all groups which revealed a statistically significant difference $(p<0.05)$ between all groups. Tukey test for multiple comparisons was also performed to differentiate between each group in relation to the other 3 groups and revealed statistically significant difference among groups.

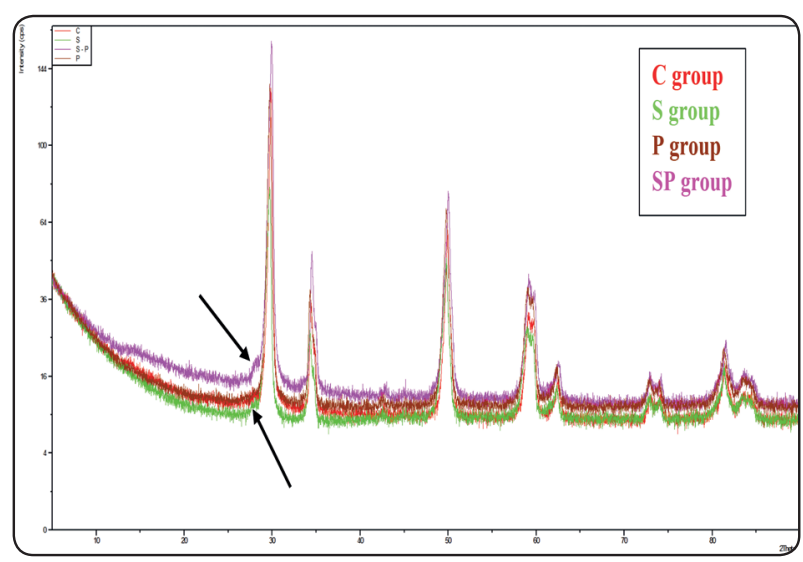

Fig. (2) XRD analysis of the different surface treatment methods. The arrows represent the monoclinic phase.

TABLE (1) Means and standard deviations in MPa for biaxial flexure strength of all groups (one way ANOVA and Tukey tests)

\begin{tabular}{|c|c|c|c|c|c|}
\hline & C group & S group & P group & SP group & test of sig. \\
\hline Mean \pm SD & $462.11 \pm 17.33^{\mathrm{a}}$ & $310.33 \pm 7.78^{\mathrm{b}}$ & $443.34 \pm 11.73^{\mathrm{c}}$ & $412.96 \pm 11.88^{\mathrm{d}}$ & $\mathrm{F}=286.43$ \\
$\mathrm{P}<0.001^{*}$
\end{tabular}

The same superscripts indicate insignificant different pairs of values.

\section{DISCUSSION}

The ceramic material used in this study was a super translucent zirconia where the manufacturer claims high strength combined with high esthetics. The surface treatments used were airborne particle abrasion and/or primer application as they were reported to perform better adhesion with the adhesive resin cements. ${ }^{7,11}$

XRD method was used to evaluate the surface structure changes and characterization in zirconia resulting from different surface treatment applications as it is considered a non-destructive reliable method. ${ }^{34}$

Biaxial flexural strength method was used as it is considered a simple and easy method to perform, their results are more precise and accurate when compared with uniaxial tests. ${ }^{35}$

Based on the results of the XRD analysis, the first hypothesis was accepted as the airborne particle abrasion resulted in phase transformation from tetragonal to monoclinic on the surface of the super translucent zirconia in groups $\mathrm{S}$ and $\mathrm{SP}$, while the $\mathrm{C}$ 
and $\mathrm{P}$ groups showed no phase transformation. This tetragonal to monoclinic transformation may occur when an external mechanical stress is applied on the zirconia surface. ${ }^{36}$ The results of this study were in accordance with those of Kosmac et al ${ }^{23}$, Moon et al ${ }^{5}$, Jain et al ${ }^{24}$ although they used conventional and translucent zirconia and Inokoshia et al ${ }^{37}$ who used high translucent zirconia.

Regarding the results of the biaxial flexure strength, the second hypothesis was also accepted as the different surface treatments affected the strength of super translucent zirconia. Based on the statistical analysis of the results, the control group showed the highest value of biaxial flexure strength while the airborne particle abraded group showed the lowest value, this may be attributed to the effect of air blasting which produce micro cracks on the zirconia surface and due to the transformation of tetragonal to monoclinic phase. These surface flaws affect the mechanical behavior of the zirconia negatively resulting in decreased flexure strength values. The results of this study were in accordance with those of Wang ${ }^{38}$ although he used 50 and 120 $\mu \mathrm{m}$ aluminum oxide particles at $0.35 \mathrm{MPa}$ pressure for 25 seconds at $20 \mathrm{~mm}$ distance. Also, Monaco ${ }^{39}$ results agreed with this study, he used $30 \mu \mathrm{m}$ silica-coated alumina particles and 50 and $120 \mu \mathrm{m}$ aluminum oxide particles at $0.35 \mathrm{MPa}$ pressure for 25 seconds at $15 \mathrm{~mm}$ distance. Yoshida et al ${ }^{29}$ was also in agreement with this study, they used $50 \mu \mathrm{m}$ $\mathrm{Al}_{2} \mathrm{O}_{3}$ at $0.1,0.15,0.2$, and $0.3 \mathrm{MPa}$ for 15 seconds.

However, there were disagreement with the results of Fonseca et al ${ }^{40}$ as they used 30 and 110 $\mu \mathrm{m}$ silica-modified $\mathrm{Al}_{2} \mathrm{O}_{3}$, and $110 \mu \mathrm{m} \mathrm{Al}_{2} \mathrm{O}_{3}$ at 0.28 MPa for 20 seconds, Jain et al ${ }^{24}$ who used $30 \mu \mathrm{m}$ silica-coated alumina particles at $0.28 \mathrm{~mm}$ pressure and Yilmaz et al ${ }^{41}$ who used $110 \mu \mathrm{m} \mathrm{Al}_{2} \mathrm{O}_{3}$ at 2 bars for 20 seconds and used four-point flexural strength test. All of them found that the airborne particle abrasion increased the flexural strength of zirconia which may be due to the difference in particle size, pressure applied, type of flexure strength test used, and type of zirconia used.
The SP group showed higher flexural strength than the $S$ group although the surface characterization of both groups revealed tetragonal to monoclinic transformation also both groups were subjected to the same airborne particle abrasion procedure, this may be attributed to the application of the zirconia primer which may seal the initially formed micro cracks and chemically bond to the zirconia surface.

\section{CONCLUSIONS}

Within the restrictions of this in-Vitro study, it was deduced that:

1. The airborne particle abrasion of super translucent zirconia resulted in phase transformation from tetragonal to monoclinic.

2. Airborne particle abrasion has a negative effect the flexural strength of super translucent zirconia.

3. The application of zirconia primer on air abraded super translucent zirconia counter acts the negative effect of air abrasion on the biaxial flexural strength.

\section{REFERENCES}

1. Christensen GJ. Is the rush to all-ceramic crowns justified? J Am Dent Assoc. 2014;145(8):192-194.

2. Miyazaki T, Nakamura T, Matsumura H, Ban S, Kobayashi T. Current status of zirconia restoration. J. Prosthodont. Res. 2013;57: 236-261.

3. Zhang Y, Lawn BR. Novel zirconia materials in dentistry. J. Dent. Res. 2018; 97: 140-147.

4. Shahmiri R, Standard OC, Hart JN, Sorrell CC. Optical properties of zirconia ceramics for esthetic dental restorations: A systematic review. J. Prosthet. Dent. 2018; 119: 36-46.

5. Moon J, Kim S, Lee J, Han J, Yeo I, Ha S. Effects of airborne-particle abrasion protocol choice on the surface characteristics of monolithic zirconia materials and the shear bond strength of resin cement. Ceramics International 2016; 42: 1552-1562.

6. Russo DS, Cinelli F, Sarti C, Giachetti L. Adhesion to zirconia: A systematic review of current conditioning methods and bonding materials. Dent. J. 2019, 7, 74; doi:10.3390/dj7030074. 
7. Blatz MB, Sadan A, Kern M. Resin-ceramic bonding: A review of the literature. J. Prosthet. Dent. 2003; 89: 268-274.

8. Kern M, Wegner SM. Bonding to zirconia ceramic: Adhesion methods and their durability. Dent. Mater. 1998; 14: 64-71.

9. Sato H, Yamada K, Pezzotti G, Nawa M, Ban S. Mechanical properties of dental zirconia ceramics changed with sandblasting and heat treatment. Dent. Mater. J. 2008; 27: 408-414.

10. Mattiello R, Coelho T, Insaurralde E,Coelho A, Insaurralde E,Coelho A, Terra G,Kasuya A, Favarão E, Gonçalves L, Fonseca R. A review of surface treatment methods to improve the adhesive cementation of zirconia-based ceramics. ISRN Biomaterials.2013: 1-10 Hindawi Publ. Corp.

11. Shimizu H, Inokoshi M, Takagaki T, Uo M, Minakuchi S. Bonding efficacy of 4-META/MMA-TBB resin to surface-treated highly translucent dental zirconia. J. Adh. Dent. 2018; 20: 453-459.

12. Valente F, Mavriqi L, Traini T. Effects of 10-MDP Based Primer on Shear Bond Strength between Zirconia and New Experimental Resin Cement. J. Mater. 2020; 13: 235-348.

13. Obradoviæ-Djurièiæ K, Mediæ V, Dodiæ S, Gavrilov D, AntonijeviæD, Zriliæ M. Dilemmas in Zirconia Bonding: A Review. Srp Arh Celok Lek. 2013; 141:395-401.

14. Silva L, Costa A, Queiroz J, Bottino M, Valandro L. Ceramic primer heat-treatment effect on resin cement/Y-TZP bond strength. Oper. Dent. 2012; 37: 634-640.

15. Ruales-Carrera E, Cesar P, Henriques B, Fredel M, Ozcan M, Volpato C. Adhesion behavior of conventional and high translucent zirconia: Effect of surface conditioning methods and aging using an experimental methodology. J of Esthetic and Rest. Dent. 2019; 31:388-397.

16. Minh LE, Larsson C, Papia E. Bond strength between MDP-based cement and translucent zirconia. Dental Mater. J. 2019; 38: 480-489.

17. Russo DS, Cinelli F, Sarti C, Giachetti L. Adhesion to zirconia: A systematic review of current conditioning methods and bonding materials. Dent. J. 2019; 7, 74; doi:10.3390/dj7030074.

18. 18-Blatz MB, Sadan A, Arch GH, Lang BR. In vitro evaluation of long-term bonding of procera AllCeram alumina restorations with a modified resin luting agent. J. Prosthet. Dent. 2003; 89: 381-387.
19. Vargas MA, Bergeron C, Diaz-Arnold A. Cementing allceramic restorations: Recommendations for success. J. Am. Dent. Assoc. 2011; 142: 20S-24S.

20. Luthardt R, Holzhüter M, Sandkuhl O, Herold V, Schnapp J, Kuhlisc, E, Walter M. Reliability and properties of ground Y-TZP-zirconia ceramics. J. Dent. Res. 2002; 81: 487-491.

21. Wang H, Aboushelib MN, Feilzer AJ. Strength influencing variables on CAD/CAM zirconia frameworks. Dent. Mater. 2008; 24: 633-638.

22. Papia E, Larsson C, du Toit M, Vult von Steyern P. Bonding between oxide ceramics and adhesive cement systems: A systematic review. J Biomed Mater Res B Appl Biomater. 2014; 102: 395-413.

23. Kosmac T, Oblak C, Jevnikar P, Funduk N, Marion L. The effect of surface grinding and sandblasting on flexural strength and reliability of Y-TZP zirconia ceramic. Dent Mater 1999; 15:426-433.

24. Kosmac T, Oblak C, Jevnikar P, Funduk N, Marion L. Strength and reliability of surface treated Y-TZP dental ceramics. J Biomed Mater Res 2000; 53:304-313.

25. Jain T, Porwal A, Babu S, Khan Z, Kaur C, Jain R. Effect of different surface treatments on biaxial flexural strength of Yttria-stabilized tetragonal zirconia polycrystal. J. Contemp. Dent. Prac. 2018; 19:318-323.

26. Guazzato M, Quach L, Albakry M, Swain MV. Influence of surface and heat treatments on the flexural strength of Y-TZP dental ceramic. J. Dent. 2005; 33: 9-18.

27. Fonseca, R.G.; de Oliveira Abi-Rached, F.; dos Santos Nunes Reis, J.M.; Rambaldi, E.; Baldissara, P. Effect of particle size on the flexural strength and phase transformation of an airborne-particle abraded yttria-stabilized tetragonal zirconia polycrystal ceramic. J. Prosthet. Dent. 2013; 110: 510-514.

28. McLaren EA, Lawson N, Choi J, Kang J, Trujillo C. New high translucent cubic-phase-containing zirconia: clinical and laboratory considerations and the effect of air abrasion on strength. Compend Contin Educ Dent. 2017;38: e13-16.

29. Yoshida K. Influence of alumina air-abrasion for highly translucent partially stabilized zirconia on flexural strength, surface properties, and bond strength of resin cement. J Appl Oral Sci. 2020; 28: e20190371.

30. Dawood L, Atout A. Evaluation of shear bond strength between different veneering techniques and ceramic repair 
system using different surface treatment protocols. EDJ. 2016; 62:720-727.

31. Garvie RC, Nicholson PS. Phase analysis in zirconia systems. J. Am. Ceram. Soc. 1972; 55: 303-305.

32. Toraya H, Yoshimura M, Somiya S. Calibration curve for quantitative analysis of the monoclinic-tetragonal $\mathrm{ZrO} 2$ system by X-ray diffraction. J. Am. Ceram. Soc. 1984; 67: 119-121.

33. Int. Org. Standard., ISO 6872, "Dentistry - ceramic materials", Geneva, 2008.

34. Bunaciu AA, Udriştioiu EG, Aboul-Enein HY. X-Ray Diffraction: Instrumentation and Applications. Critical Reviews in Analytical Chemistry, 2015;45:4, 289-299.

35. Mijoska A, Popovska M. Evaluation of different in vitro testing methods for mechanical properties of veneer ceramics. ÏĐÈËÎÇÈ, Îää. ìåä. íâôèè, XXXVI 1, 2015. Contributions, Sec. Med. Sci. 2015; XXXVI 1.

36. Kobayashi K, Kuwajima H, Masaki T, Phase change and mechanical properties of $\mathrm{ZrO}_{2}-\mathrm{Y}_{2} \mathrm{O}_{3}$ solid electrolyte after ageing, Solid State Ionics 1981;3:489-493.
37. Inokoshia M, Shimizua H, Nozakib K, Takagakic T, Yoshiharad K, Nagaokae N, Zhang F, Vleugels J, Meerbeek B, Minakuchia S. Crystallographic and morphological analysis of sandblasted highly translucent dental zirconia. Dent Mater. 2018; 34:508-518.

38. Wang H. Strength testing variables in dental ceramics. $\mathrm{PhD}$ thesis. Faculty of Dentistry (ACTA), Universiteit van Amsterdam, Netherlands, 2008.

39. Monaco C. Zirconia in dentistry: Microstructural changes produced by abrading Y-TZP in pre-sintered and sintered conditions. PhD thesis. Faculty of Engineering, Universita’ Di Bologna, Bologna, 2012.

40. Fonseca R, Abi-Rached F, da Silva F, Henriques B, Pinelli L. Effect of surface treatments on the biaxial flexural strength and phase transformation of a Y-TZP ceramic. J Adhes. Dent. 2014; 16:451-458.

41. Yilmaz S, Önöral Ö, Aktore H, Ozan O. Does the application of surface treatments in different sintering stages affect flexural strength and optical properties of zirconia? J Esthet Restor Dent. 2020; 32:81-90. 